\title{
Effect of Pyridoxal 5-Phosphate on the Activity of GOT Isozyme in Plasma from Patients with Duchenne Muscular Dystrophy
}

\author{
Hideki Ohno, Naoyuki Taniguchi, * Kazuyuki Terayama, \\ Fumiko Hirata, Tadao Kawarabayashi, Sanji Miyoshino ${ }^{\dagger}$ \\ and Ichiro Matsuda $\dagger$ \\ Department of Hygiene and Preventive Medicine, Asahikawa \\ Medical College, Asahikawa 078-11, *Biochemistry Laboratory, \\ Cancer Institute, Hokkaido University School of Medicine, \\ Sapporo 060, and †Department of Pediatrics, Kumamoto \\ University Medical School, Kumamoto 860
}

Ohno, H., Taniguchi, N., Terayama, K., Hirata, F., Kawarabayashi, T., Mryoshino, S. and Matsuda, I. Effect of Pyridoxal 5-Phosphate on the Activity of GOT Isozyme in Plasma from Patients with Duchenne Muscular Dystrophy. Tohoku J. exp. Med., 1981, 135 (3), 333-334 - GOT isozyme (soluble GOT, s-GOT and mitochondrial GOT, m-GOT) activities with and without reactivation by the co-enzyme pyridoxal 5-phosphate (PALP) in plasma from 42 patients with Duchenne muscular dystrophy (DMD), and 11 normal controls were investigated. The magnitude of the enzyme activities in patients at the early stage of DMD greatly exceeded those of controls. As the disease progressed, the levels gradually declined, but late stage values were still higher than the control values except s-GOT with PALP. At the mid stage as well as the late stage, the increase in m-GOT activity was approximately to double the unstimulated activity, indicating that, in these patients, as much as half the m-GOT in the circulation was in the inactive apoenzyme form, whereas s-GOT showed negligible increase following PALP addition at any stage. - m-GOT and s-GOT isozyme; pyridoxal 5-phosphate; Duchenne muscular dystrophy

Glutamic oxaloacetic transaminase (GOT) has two isozymes, one located in the cytoplasmic fraction of cells (soluble GOT, s-GOT) and the other in the mitochondria (mitochondrial GOT, m-GOT). It is known that they are different proteins with different kinetic and immunochemical properties. Since Hamfelt (1966) reported that the activity of this enzyme in sera from patients with various diseases when supplemented in vitro with the co-enzyme pyridoxal 5-phosphate (PALP) was enhanced, routine pre-incubation of sera with PALP prior to GOT determination has been recommended (Moss 1976). However, we have no report about the activation by PALP of GOT isozyme activities in clinical diagnosis with one exception (Kamei et al. 1978). In Duchenne muscular dystrophy (DMD) the release of certain enzymes, e.g., GOT and creatine phosphokinase, from skeletal muscle cells into the blood serum is well known. In the present study experiments on the effect of PALP on the GOT isozyme activities of plasma from patients with DMD were performed.

Forty-two male patients suffering from DMD were studied. These cases, aged from 7 to 24 years, were classified into the early stage (patients able to walk, $n=12$ ), the mid stage (patients able to sit, $n=28$ ), and the late stage (bedridden patients, $n=2$ ) of the

Received for publication, March 30, 1981. 
TABLE 1. GOT isozyme activity with and without reactivation by pyridoxal 5-phosphate

\begin{tabular}{|c|c|c|c|c|}
\hline \multirow{3}{*}{ Subjects } & \multicolumn{2}{|c|}{ m-GOT (Karmen units/ml) } & \multicolumn{2}{|c|}{ s-GOT (Karmen units/ml) } \\
\hline & PALP not added & Incr & PALP not added & Inc \\
\hline & PALP added & $(\%)$ & PALP added & $\mathbf{P} A$ \\
\hline Control $(n=11)$ & $\begin{array}{l}5.7 \pm 0.2 \\
9.1 \pm 0.4\end{array}$ & $60.7 \pm 5.5$ & $\begin{array}{r}9.5 \pm 0.8 \\
11.4 \pm 1.0\end{array}$ & $20.3 \pm 3.5$ \\
\hline $\begin{array}{l}\text { Patients with DMD } \\
\text { Early stage }(n=12)\end{array}$ & $\begin{array}{l}16.9 \pm 2.3^{\mathrm{c}} \\
29.1 \pm 3.5^{\mathrm{c}}\end{array}$ & $80.9 \pm 9.4$ & $\begin{array}{l}67.3 \pm 10.9^{\mathrm{c}} \\
74.4 \pm 9.9^{\mathrm{c}}\end{array}$ & $15.9 \pm 5.1$ \\
\hline Mid stage $(n=28)$ & $\begin{array}{l}10.9 \pm 0.5^{\mathrm{c}} \\
21.2 \pm 0.9^{\mathrm{c}}\end{array}$ & $102.5 \pm 9.7^{\mathrm{c}}$ & $\begin{array}{l}30.0 \pm 2.4^{\mathrm{c}} \\
31.7 \pm 3.1^{\mathrm{c}}\end{array}$ & $8.4 \pm 6.3$ \\
\hline Late stage $(n=2)$ & $\begin{array}{r}8.9 \pm 1.2^{\mathrm{a}} \\
18.8 \pm 3.3^{\mathrm{b}}\end{array}$ & $127.5 \pm 56.0$ & $\begin{array}{l}16.5 \pm 2.3^{\mathrm{b}} \\
18.5 \pm 4.7\end{array}$ & $10.6 \pm 14.0$ \\
\hline
\end{tabular}

Values are expressed as mean \pm s.E. Significantly different from the control: ${ }^{a} p<0.05$, ${ }^{\mathrm{b}} p<0.02,{ }^{\mathrm{c}} p<0.001$.

disease. Eleven healthy male volunteers, aged from 18 to 24 years, served as controls. m-GOT isozyme was separated according to the method described by Wada et al. (1976). GOT activity with and without PALP was measured by the Boehringer GOT-UV-Test (Mannheim) using a Hitachi 624 spectrophotometer after 10 min pre-incubation at $37^{\circ} \mathrm{C}$. The effect of PALP addition was investigated by a slight modification of the methods of Moss (1976) and Kamei et al. (1978). The final PALP concentration was $100 \mu$ moles/liter.

As shown in Table 1, plasma GOT isozyme activities with and without reactivation by PALP were greatly increased in patients at the early stage of DMD. As the disease progressed, the levels gradually declined in agreement with our previous report (Matsuda et al. 1978). However, at the late stage, although only two patients were classified into this group, the enzyme levels were still higher than the control values except s-GOT with PALP. Inversely, the effect of PALP addition on m-GOT activity gradually increased as the disease advanced, whereas s-GOT showed little increase following PALP addition at any stage. At the mid stage as well as the late stage, the increase in m-GOT activity was approximately to double the unstimulated activity, indicating that, in these patients, as much as half the m-GOT in the circulation was in the inactive apoenzyme form. These findings may suggest that pre-incubation of sera with co-enzyme pyridoxal phosphate should be routinely employed in GOT isozyme determination for diagnostic purposes of various diseases.

\section{References}

1) Hamfelt, A. (1966) The effect of pyridoxal phosphate on the aminotransferase assay in blood. Scand. J. clin. Lab. Invest., 18, Suppl. 92, 181-188.

2) Kamei, S., Okubo, A., Sasaoka, S., Koike, S., Yamanaka, M., Kawano, N. \& Iwasaki, Y. (1978) Clinical evaluation of apoenzymes of aspartate aminotransferase isozymes in serum. Jap. J. clin. Chem., 6, 164-169. (Japanese)

3) Matsuda, I., Miyoshino, S., Miike, T., Nagata, N., Tamari, H., Taniguchi, N., Ohno, H. \& Watanabe, H. (1978) Mitochondrial fraction of serum glutamic-oxaloacetic transaminase in Duchenne muscular dystrophy. Clin. chim. Acta, 83, 231-234.

4) Moss, D.W. (1976) Reactivation of the apoenzyme of aspartate aminotransferase in serum. Clin. chim. Acta, 67, 169-174.

5) Wada, H., Teranishi, H., Kagamiyama, H., Ohyanagi, H., Shirakawa, M., Mitsuno, T., Fuse, K. \& Sawada, Y. (1976) A simple immunological method for differential determination of serum GOT-isozymes and its clinical application. Abstracts of 10th Int. Congr. of Biochemistry, Hamburg, p. 589. 